\title{
ALTERNATE VENDOR DEVELOPMENT OF CYCLOSERINE API
}

\author{
Dinesh Kaushik
}

\begin{abstract}
Alternative Vendor development is essential strategy for buying of material in right quantity, of right quality, at right price from a right source, at right time and place. Thus, source selection begins after the user department forwards material requisition form to purchase department. The purchase department thus, calls quotations, invites tenders, receives and processes them. The comparative statements, on the basis of offers made must exhibit in addition to price differentials, a brief history of tenders in respect of their quality standards dependability and performance reliability. After critical examination of all the aspects based on information supplied by them, a particular vendor is selected who can establish suitability criterion in most effective manner. On asking, selected vendor generally supply "initial sample". If approved, this would then be followed by "initial supply". The evaluation of initial supply results should be supplemented by on-the-spot study team visits at the vendor's plant consisting of production engineers, quality controllers, cost-accountants and finance expert. The team should make a detailed study of processes, organization and other allied matters necessary for vendor evaluation. This composite scheme would then form the basis for vendor selection rather than by results of a single sample as practiced in many organizations. On the basis of this study, bulk supply orders should follow.
\end{abstract}

Keywords: AVD, pharmaceutical formulations, API, Vendor Development and dosage forms.

\section{INTRODUCTION:}

In pharmaceutical industries, there are various raw material used to require for the formulation of the products. Manufactures does require various APIs, excipients, packing materials, machineries and other raw material to launch their product in marker. Any drug is composed of two components or aspects. The first is the actual API or Active Pharmaceutical Ingredients, which is the central ingredient. The second is known as an excipient. This refers to the substance inside the drug or tablet. API also refers to the active or central ingredient in the product which causes the direct effect on the disease diagnosis, prevention, treatment or cure. While API is the active component of a drug, excipients are the inactive or inert substances present in a drug. An API starting material can be an article of commerce, a material purchased from one or more vendors under contract or commercial agreement, or produced in-house. API starting materials normally have defined chemical properties and structure. The company should designate and document the rationale for the point at which production of the API begins. For synthetic processes, this is known as the point at which "API Starting Materials" are entered into the process. For other processes (e.g. fermentation, extraction, purification, etc.), this rational should be established on a case-by-case basis.

\footnotetext{
${ }^{1}$ (Approved Manufacturing Chemist) Tablet / Capsule Section From State Drug Controller Haryana
} 
Alternate Vendor Development is an important strategy followed by Pharmaceutical industries in order to meet the continuous demand of materials for production of dosage forms. Multiple resources will come into hand when a company asks for material. The important step now is to select the material from this group of vendors such that they meet the company's desired specification.

Two of the important responsibilities for the purchasing executive are

1. To select the right source of supply.

2. To develop new suppliers.

In other words, supplier selection and new source development are major contributions of the purchasing function and so should have properly planned approach. A good supplier actively participates and helps the purchase to meet his customer's requirements.

Suppliers also contribute their specialized knowledge and help build quality into the purchasing company's products. For the selection, it is easy for purchaser to work out a preference pattern based on price, quality, and delivery, service land his geographic allocation, his technical ability and knowledge. The suppliers may be large, medium or small, who supplies raw materials, component, equipment, etc.

\section{Reasons for the AVD:}

$\checkmark \quad$ To break the monopoly of the existing product.

$\checkmark \quad$ To reduce the cost of the product.

$\checkmark \quad$ To improve the Quality of the product.

$\checkmark \quad$ To reach the continuous market demand of the product.

$\checkmark \quad$ To maintain the supply of the product for consumer in time.

AVD is very important in pharmaceutical industry because of the changes occurred in the manufacturing of pharmaceutical products. ${ }^{[1,2]}$

\section{VENDOR QUALIFICATION AND QUALITY SYSTEMS:}

The qualification process is defined by the American Society for quality Control (ASQC) as "the process of demonstrating whether an entity is capable of fulfilling the specified requirement." Vendor qualification is the process by which a vendor is evaluated to determine if it can provide the necessary good or services to the standards that the purchasing company requires.

Before discussing the best approach to qualifying different types of vendors, it is important to first understand the concept of quality systems. Quality systems are defined as "The processes, organizational structure, procedures and resources that are used to control variables associated with producing a product of consistent quality and that meets predefined specifications." In simpler words, an organization's entire operation is a measure of a products quality and not simply the testing of its finished product. This Q.U.E.S.T. approach is a simple, effective, and compliant approach to vendor qualification. ${ }^{[3]}$

\section{VENDOR QUALIFICATION, THE Q.U.E.S.T. APPROACH:}

1. $\quad \mathrm{Q}=$ Question Phase : What a potential vendor needs to supply The first step in qualifying a vendor is for the pharmaceutical or biopharmaceutical company to document its needs from a vendor of this type. For example, does the vendor need to sell to pharmaceutical or biopharmaceutical firms already? Does the vendor have to have a drug master file registered with the US Food and Drug administration? 
2. $\quad \mathrm{U}=$ Understanding Phase: How vendors meet the requirements Once the Question Phase is complete, Vendors that appear to meet the company's requirements are contacted directly to gauge interest in being a new vendor for the company, The company's requirements ( as defined in the Question Phase) are then supplied to those interested vendor organizations. It should be requested that the vendor supply all its administrative information (e.g., key contacts, locations (S)

3. $E=$ Evaluation Phase: Identification of the best potential vendor. Now that at least three vendors have been identified to meet the company's requirements, is time for vendor evaluation.

4. $\quad \mathrm{S}=$ Site Audit Phase: Onsite verifications

Vendor types need to be divided into critical and noncritical suppliers. A critical vendor is one that supplies goods or services that directly controls or dictates the quality and integrity of pharmaceutical and biopharmaceutical products. A noncritical vendor is one that supplies goods or services that assist and support the quality of these products.

Manufacture of Medicinal Products and the Active Pharmaceutical Ingredients (APIs) used as starting materials in the production of these products is subject to strict good manufacturing practice regulations that are designed to ensure their quality, safety and efficacy. This ensures that patients worldwide and at any time can have confidence in the quality, safety and efficacy of medicines. ${ }^{[5]}$

The c-GMP regulations for final medicinal products are clearly defined in each country and region. The content of the regulations may vary but the objectives are the same:

To deliver high quality, safe medicines manufactured and distributed following controlled procedures to treat diseases.

To prevent deaths, serious illnesses, adverse events or product recalls resulting from deficiencies in the manufacturing and distribution processes. ${ }^{[2]}$

\section{API DEVELOPMENT PROCESS:}

From this point on, appropriate GMP as defined in this guide should be applied to these intermediate and/or API manufacturing steps. This would include the validation of critical process steps determined to impact the quality of the API. However, it should be noted that the fact that a company chooses to validate a process step does not necessarily define that step as critical. Records should be maintained including the name of the manufacturer, identity and quantity of each shipment of each batch of raw materials, intermediates or labeling and packaging materials for API's; the name of the vendor; the vendor's control number(s), if known, or other identification number; the number allocated on receipt; and the date of receipt. ${ }^{[5]}$

Two important responsibilities of the purchasing department are

1. To select the right source of supply of material.

2. To develop new vendors.

Vendor selection and new source development are major contributions of the purchasing function and so should be properly planned approach. A good vendor actively participates and helps the purchase to meet the customer's requirements. Vendors also contribute their specialized knowledge and help build quality into the purchasing company's products. For the selection, it is easy for purchaser to work out a preference pattern based on price, quality, and delivery service land his geographical location, his technical ability and knowledge. The vendors may be large, medium or small, who supplies raw materials, component, equipment, etc. The factors which were considered to evaluate the functional aspects of vendor's selection are: 
A. High Impact Factors:

$\checkmark \quad$ Delivery Reliability

$\checkmark \quad$ Quality / price ratio

B. Factors with middle values

$\checkmark \quad$ General reputation

$\checkmark$ Geographical location

$\checkmark \quad$ Technical ability and knowledge

$\checkmark \quad$ Technical inventiveness

$\checkmark \quad$ Supply of information and market surveys

$\checkmark \quad$ Extent of previous contact with the buyers.

C. Low Rated Factors:

$\checkmark \quad$ Importance as a client (reciprocity)

$\checkmark \quad$ Extent of personal benefits to the buyer.

D. Sources of Supply Information [5]

The sources of supply information are

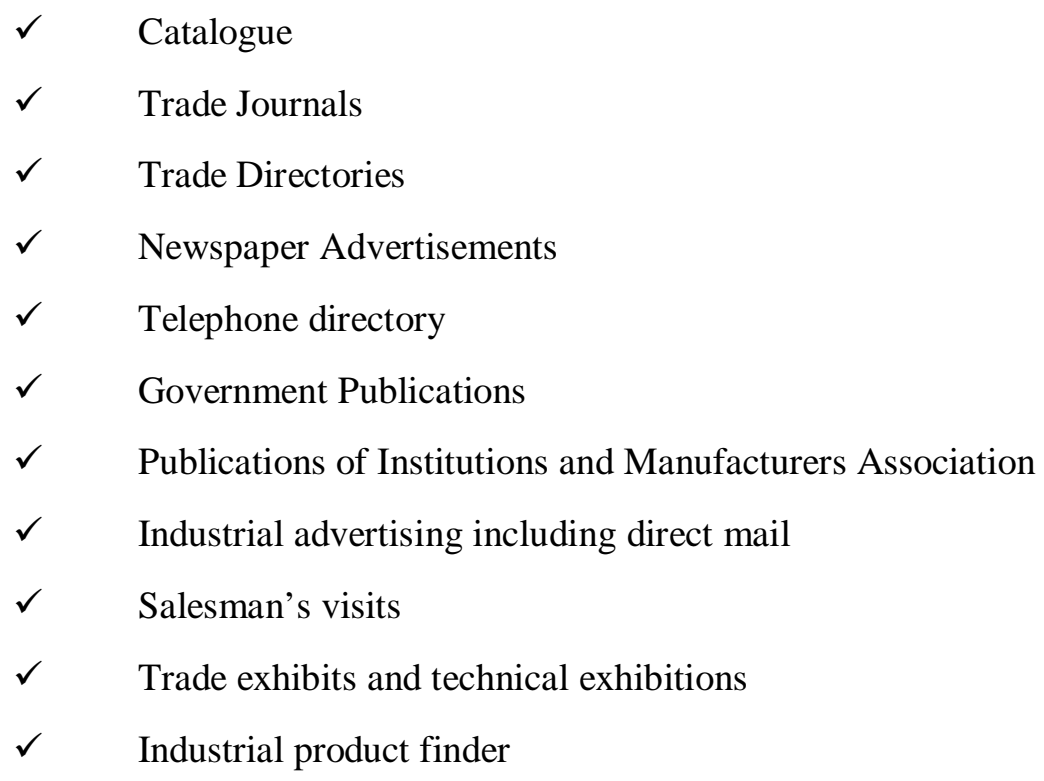

Sources of supply covering equipment, materials, price information and other details may be extracted from the above. All these, if indexed, properly filed and periodically updated, serve as a good reference, not only to the purchasers but to others in the organization. The indexing should be based on product information and according to the names of vendors and geographical purchasers should be fully aware the information of new product, new processes contained in these.

The vendor / vendors may be large, medium or small companies and further they can broadly classify as suitable for 


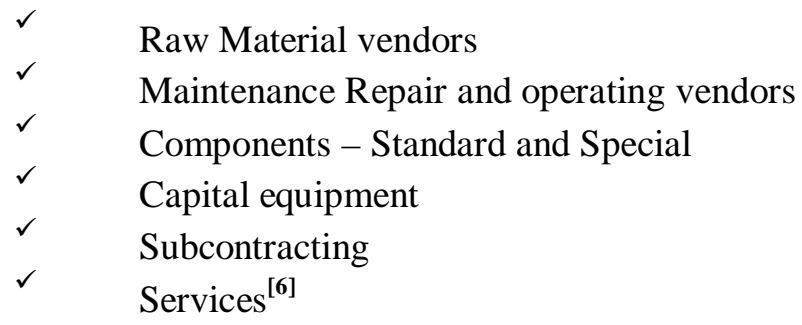

\section{E. Types of vendors in pharmaceutical manufacturing industry}

\section{I.Approved Vendors}

Those who meet the applicable criteria of the approval process for specific materials from a specific manufacturing site are known as approved vendors.

\section{II.Disapproved Vendors}

Those who do not meet the criteria of SOP for approved vendor or eligible for disapproval as per applicable criteria of SOP for a specific material are known as disapproved vendors.

\section{III.Additional Vendors}

An extra vendor to be added to a group of existing vendor for a specific material is known as additional vendors.

\section{I.New Vendors}

First time vendors to be approved for a specific material are known as new vendors. ${ }^{[6]}$

F.

\section{Process Development Lab (PDL) role in vendor change}

I.Create material code for materials from additional vendors.

II.Produce test batches using raw material and packing material from additional vendors.

III.Taking trial batches by using raw material from new vendors.

G. Vendors to be approved is categorized as given below

I.New vendor for new materials

II.Additional vendor for existing materials

III.Existing approved vendor for new materials ${ }^{[6]}$

\section{BENEFITS OF SUPPLIER DEVELOPMENT:}

1. Cost Reduction.

2. Productivity improvement.

3. Buyer performance improvement.

4. Improvement in quality.

5. Learn manufacturing capability improvement

6. Reduction in cycle time.

7. Operation improvement.

8. Reduction in defective products.

9. Collaboration between buyer and supplier

10. Learning and knowledge transfer.

11. Optical resource utilization.

12. Competitive advantage. 
13. Supplier Performance $e^{[5]}$

\section{CYCLOSERINE DRUG PROFILE:}

Cycloserine (4-amino-3-isoxazolidinone) is a broad spectrum antibiotic used as a second line agent for treatment of drug resistant tuberculosis, always in combination with other anti-tuberculosis agents. Cycloserine is appears to have little or no hepatotoxic potential, but it is usually used in combination with agents that are known to be hepatotoxic, and its role in the reported cases of liver injury with combination therapy cannot always be excluded.

Cycloserine (sye" kloe ser' een) is an antibiotic that is currently used largely in the therapy of tuberculosis caused by multidrug resistant mycobacteria. Cycloserine is a d-alanine analogue of isoxazolidone that was isolated initially from Streptococcus orchidaceous and has moderate activity in vitro against mycobacterial species, probably acting by inhibition of mycobacterial use of amino acids and inhibition of cell wall synthesis. Importantly, there is no cross resistance between cycloserine and most other medications for tuberculosis. Cycloserine was approved for use in the United States in 1964, but its use for most indications has been replaced by more modern anti tuberculosis agents except in instances of multidrug resistance or of intolerance to the more potent agents such as isoniazid, rifampin and pyrazinamide. Cycloserine is available in tablets of $250 \mathrm{mg}$ in generic forms and under the brand name Seromycin; the typical adult dose is 250 to $500 \mathrm{mg}$ twice daily $(\sim 10-15 \mathrm{mg} / \mathrm{kg} /$ day $)$. Common side effects are drowsiness, headache, fatigue, rash and fever; rarely, cycloserine causes more serious neurological side effects such as acute psychosis, seizures and coma. ${ }^{[4]}$
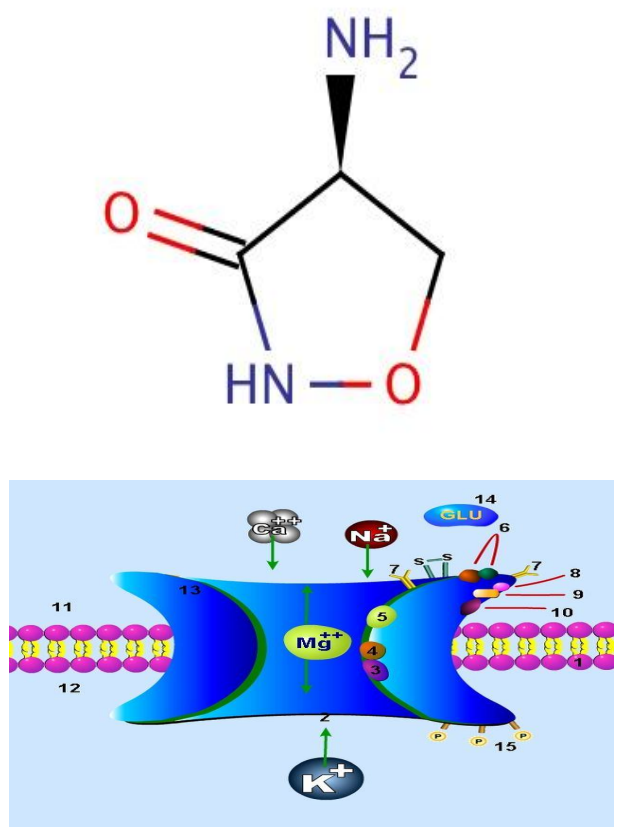

\section{MECHANISM OF ANTIBIOTIC ACTION:}

Cycloserine works as an antibiotic by inhibiting cell-wall biosynthesis in bacteria. As a cyclic analogue of D-alanine, Cycloserine acts against two crucial enzymes important in the cytosolic stages of peptidoglycan synthesis: alanine racemase (Alr) and D-alanine: D-alanine ligase (Ddl). The first enzyme is a pyridoxal 5'-phosphate-dependent enzyme which converts the L-alanine to the D-alanine form. The second enzyme is involved in joining two of these D-alanine residues together by catalyzing the formation of the ATP-dependent D-alanine- $\mathrm{D}$-alanine dipeptide bond between the resulting D-alanine 
molecules. If both of these enzymes are inhibited, then D-alanine residues cannot form and previously formed D-alanine molecules cannot be joined together. This effectively leads to inhibition of peptidoglycan synthesis in Gram-positive bacteria. ${ }^{[4]}$

\section{CLINICAL PARTICULAR:}

\section{- Therapeutic indications:}

Actions: Cycloserine inhibits cell wall synthesis in susceptible strains of Gram-positive and Gramnegative bacteria and in Mycobacterium tuberculosis.

Indications: Cycloserine is indicated in the treatment of active pulmonary and extra-pulmonary tuberculosis (including renal disease) when the organisms are susceptible to this drug and after failure of adequate treatment with the primary medications (streptomycin, isoniazid, rifampicin and ethambutol). Like all anti-tuberculosis drugs, Cycloserine should be administered in conjunction with other effective ${ }^{4}$

Toxicity is usually associated with blood levels of greater than $30 \mathrm{mg} / \mathrm{l}$, which may be the result of high dosage or inadequate renal clearance. The therapeutic index for this drug is low. The risk of convulsions is increased in chronic alcoholics (see 'Precautions' section).

Patients should be monitored by haematological, renal excretion, blood level and liver function studies.

Before treatment with Cycloserine is begun, cultures should be taken and the susceptibility of the organism to the drug should be established. In tuberculosis infections, sensitivity to the other antituberculosis agents in the regimen should also be demonstrated.

Blood levels should be determined at least weekly for patients having reduced renal function, for individuals receiving a daily dosage of more than $500 \mathrm{mg}$, and for those showing signs and symptoms suggestive of toxicity. The dosage should be adjusted to keep the blood level below 30mg/l.

Anticonvulsant drugs or sedatives may be effective in controlling symptoms of central nervous system toxicity, such as convulsions, anxiety or tremor. Patients receiving more than 500mg of Cycloserine daily should be closely observed for such symptoms. The value of pyridoxine in preventing CNS toxicity from Cycloserine has not been proven.

Administration of Cycloserine and other anti-tuberculosis drugs has been associated in a few instances with vitamin B12and/or folic acid deficiency, megaloblastic anemia and sideroblastic anemia. If evidence of anemia develops during treatment, appropriate investigations and treatment should be carried out.

Cycloserine has been associated with clinical exacerbations of porphyria and is not recommended in porphyric patients. ${ }^{3}$

\section{Manufacturing Steps:}

Trial batch of the Cycloserine IP carried out with following steps:

1. Dispensing and checking of weights

2. Geometrical mixing and Sifting

3. Mixing

4. Compaction and Passing

5. Drying

6. Blending and Lubrication 
7. Capsules Filling

8. Inspection of filled capsule

9. Packing

\section{Evaluation ofCycloserine Capsule}

A. Weight variation

B. Disintegration Time

C. Uniformity of content

D. Dissolution

E. Assay

F.Stability study

Hold drug for stability study for minimum 3 month. Take Analysis data after 3 months \& then compare study with old vendor if data satisfactory then deal with new Vendor for supply Cycloserine.

\section{Comparative study between vendors:}

(A) Stability study was done after study vendor SHASUN pharmaceutical's dissolution 96\%, Assay 96.3, R.S. value is NMT 2.6.Stability study was done after study vendor Done pharmaceutical's dissolution92\%, Assay 93.5, R.S. value is NMT 3.7.

(B )Stability study was done after study vendor Lupin pharmaceutical's (Baroda) dissolution 84\%, Assay 94.7, R.S. value is NMT 4.2

C ) Stability testing was done \& after stability study we concluse that vendor SHASUN Pharmaceutical is mor satisfie Of SHASUN pharmaceutical is more satisfied then DONG A pharma ,Lupin pharm(Baroda). Cycloserine(SHASUN pharmaceutical) further used for commercial batches. 


\begin{tabular}{|c|c|c|c|}
\hline Parameter & $\begin{array}{c}\text { SHASUN } \\
\text { Pharmaceutical }\end{array}$ & $\begin{array}{l}\text { Dong } \\
\text { Pharmaceutical }\end{array}$ & $\begin{array}{l}\text { lupin Pharmaceutical } \\
\text { (Baroda) }\end{array}$ \\
\hline Description & Size ' 1 ' & Size ' 1 ' & Size ' 1 ' \\
\hline Solubility & $\begin{array}{l}\text { Freely soluble in water } \\
\text { Slightly soluble in } \\
\text { Methanol }\end{array}$ & $\begin{array}{l}\text { Freely soluble in } \\
\text { water Slightly } \\
\text { soluble in Methanol }\end{array}$ & $\begin{array}{l}\text { Freely soluble in } \\
\text { Slightly sater } \\
\text { Methanol }\end{array}$ \\
\hline $\begin{array}{l}\text { Disintegra-tion } \\
\text { Time }\end{array}$ & $8 \mathrm{~min} 48 \mathrm{sec}$ & $8 \min 56 \mathrm{sec}$ & $8 \mathrm{~min} 59 \mathrm{sec}$ \\
\hline $\begin{array}{l}\text { Weight of } 20 \\
\text { Capsules }\end{array}$ & $8.520 \mathrm{gm}$. & $8.531 \mathrm{gm}$. & $8.522 \mathrm{gm}$. \\
\hline Dissolution & $96 \%$ & $92 \%$ & $84 \%$ \\
\hline ASSAY & 96.3 & 93.5 & 94.7 \\
\hline L.O.D. & 0.61 & 0.77 & 0.81 \\
\hline Related Substance & 2.4 & 3.7 & 4.02 \\
\hline
\end{tabular}

\section{REFERENCE}

[1]. EMEA update guidance, New Variations guidance implemented in January, 2010.

[2]. Chinese SFDA: Variation guidance to pharmaceutical product, 2008.

[3]. Amidon, G.L., Lennersan, H., Shah, V.P., 1995. A theoretical basis for a biopharmaceutics drug classification the correlation of In vitro drug product and In vivo bioavailability. Pharm. Res. 12, 20-413.

[4]. http://www.cimsasia.com/India/drug/search/cycloserine

[5]. Barbarosoglu G and Tazgac T. An application of the analytic hierarchy process to the supplier selection problem, Production and Inventory Management Journal, 1997, 14-21

[6]. Krause D, handfield R, an empirical study of supplier development.1998, vol -17, page-39 to 58. 